\title{
Análise qualitativa de dados de pesquisa com foco na identificação de necessidades dos usuários.
}

Qualitative analysis of research data with focus on user needs identification.

FERRARI, Nina; Graduanda; Universidade Federal do Espírito Santo

nroberta.ferrari@gmail.com

RUFINO, Edson; Doutor; Universidade Federal do Espírito Santo

edson.rufino@gmail.com

\section{Resumo}

As metodologias de design de interação com uma abordagem centrada no usuário envolvem etapas iniciais de levantamento e análise de dados, que buscam a identificação das necessidades dos usuários e a definição dos requisitos necessários para o projeto. A partir da proposta de projeto de aplicativo para localização de árvores frutíferas em um campus universitário, foi proposta metodologia de análise qualitativa de dados obtidos na etapa de levantamento com objetivo de definição de necessidades dos possíveis usuários do aplicativo. O tratamento conferido aos dados por meio da referida análise possibilitou determinar aquilo que é mais frequentemente requisitado pelos usuários que possuem características em comum. Os resultados da análise favoreceram o desenvolvimento de perfis de usuário e a definição de requisitos de projeto para o desenvolvimento do aplicativo, com base no discurso da própria comunidade universitária.

Palavras Chave: análise qualitativa; requisitos; perfil do usuário; design de interação.

\begin{abstract}
Interaction design methodologies with a user-centered approach involve initial steps of data collection and analysis, which seek to identify users' needs and define requirements for the project. From the design proposal of application to locate fruit trees on a university campus, a methodology was proposed for the qualitative analysis of data obtained in the survey stage with the purpose of defining the needs of possible users of the application. The treatment given to the data by steps of this analysis made possible to determine what is most frequently requested by the users that have common characteristics. The results of the analysis favored the development of user profiles and the definition of design requirements for application development, based on the discourse of the university community itself.
\end{abstract}

Keywords: qualitative analysis; requirements; user profile; interaction design. 


\section{Introdução}

Segundo Rogers, Preece e Sharp (2013), os projetos de design de interação com uma abordagem centrada no usuário se caracterizam pelo uso de metodologias projetuais específicas que visam envolver os usuários que são foco do projeto em todo o processo de design.

Segundo as autoras, essas metodologias envolvem etapas iniciais de levantamento e análise de dados, que buscam a identificação das necessidades dos usuários e a definição dos requisitos necessários para o que se pretende desenvolver, e a partir destas avançar para as etapas posteriores de geração de alternativas, prototipagem e testes.

Segundo Mayhew (1999), em projetos de sistemas com foco no usuário, a etapa de definição dos requisitos é composta pela definição do perfil do usuário e suas necessidades, a análise da tarefa, as capacidades e restrições da plataforma a ser utilizada, bem como demais objetivos do projeto.

Usuários diferentes têm perfis distintos. Entender melhor os perfis de usuários, suas características comuns e necessidades relacionadas aos objetivos do projeto favorece que a solução proposta leve tais aspectos em consideração (ROGERS, PREECE e SHARP, 2013).

Neste artigo, descreve-se o método utilizado para identificar necessidades dos usuários a fim de estabelecer os requisitos funcionais no projeto de um aplicativo para smartphone. 0 problema de design a ser resolvido com o referido aplicativo é o de incentivar a colheita e o consumo de frutas por parte dos estudantes e servidores do campus de Goiabeiras da Universidade Federal do Espírito Santo (UFES), bem como auxiliar a encontrar e identificar frutos comestíveis nas árvores que constituem a área verde do campus supracitado.

Durante a etapa de levantamento de dados, foi realizada uma pesquisa por meio de aplicação de questionário composto por perguntas abertas e fechadas e, posteriormente, as respostas obtidas foram analisadas através de uma abordagem quantitativa e qualitativa.

O tratamento conferido aos dados por meio da análise qualitativa, mais precisamente, possibilitou determinar aquilo que é mais frequentemente requisitado pelos usuários que possuem características em comum, facilitando posteriormente o desenvolvimento de personas. Dessa forma foi possível estabelecer diretrizes para o desenvolvimento do aplicativo, baseado no discurso da própria comunidade universitária.

O presente artigo se propõe a apresentar o procedimento de análise dos dados da referida pesquisa por questionário, bem como discutir os achados do método de análise proposto para geração de requisitos em projetos de design de interação.

A seguir descreve-se o contexto do projeto, os métodos utilizados e discute-se os resultados obtidos.

\section{Contextualização}

Com uma área de aproximadamente $1.567 .545,00 \mathrm{~m}^{2}$, o campus de Goiabeiras da UFES possui aproximadamente quatro mil árvores e arbustos catalogados e georreferenciados, segundo dados disponibilizados pela Prefeitura Universitária.

Dentre estas, 1258 são de espécies que produzem frutos próprios para consumo in natura, isto é, sem preparo ou processamento prévio. Neste artigo, estas árvores são designadas 
simplesmente com o termo "frutíferas", conforme definição popular, diferentemente do entendimento do termo nos estudos de botânica.

Os dados georreferenciados sobre as árvores tornaram possível a concepção do projeto de aplicativo com objetivo de facilitar a localização e identificação das árvores frutíferas, incentivando a colheita e o consumo de frutas por parte da comunidade acadêmica.

A fim de melhor entender as necessidades relacionadas ao projeto, foram realizadas etapas de levantamento e análise de dados, que neste contexto consistiram em:

1. Estimar numericamente o público frequentador da universidade em questões como faixa etária e quantidade de indivíduos;

2. Aplicação de questionário online com amostra representativa e significativa do público pretendido;

3. Análise quantitativa das respostas às perguntas de caráter objetivo;

4. Análise qualitativa das respostas às perguntas de caráter discursivo;

5. Agrupamento das respostas com características similares, formando grupos de indivíduos que possuem necessidades em comum; e

6. Criação de personas a partir dos agrupamentos realizados.

O presente artigo tem como objetivo descrever o processo de análise dos dados obtidos por meio dessa etapa preliminar, enfatizando a análise das perguntas abertas do questionário aplicado, conforme descrito a seguir.

\subsection{Coleta de dados}

Dados os objetivos da pesquisa, faz-se necessário definir o tipo de abordagem a ser utilizado. Conforme classificação utilizada por Gil (2010), esta pesquisa pode ser definida como exploratória, já que se busca familiaridade com um problema pouco conhecido, isto é, a relação das pessoas com o consumo de frutas no campus.

Segundo Rudio (2002), a coleta de dados é a fase do método de pesquisa cujo objetivo é obter informações da realidade e, de acordo com o tipo de informações que se deseja obter, utilizase diferentes instrumentos de pesquisa. O questionário e a entrevista são dois instrumentos bastante utilizados em pesquisas com o público e a principal diferença entre eles, de acordo com o autor, é o fato do questionário ser necessariamente aplicado de forma escrita, enquanto na entrevista as perguntas são realizadas oralmente.

Gil (2010) defende que questionários consistem basicamente em traduzir os objetivos da pesquisa em questões específicas, buscando respostas que descrevam as características da população pesquisada. $O$ autor também aponta vantagens na aplicação de questionários em relação a outros instrumentos de pesquisa, que foram consideradas neste projeto. São elas:

1. Atingir grande número de pessoas, mesmo em lugares distintos;

2. Custo baixo; 
3. Garantia do anonimato do participante;

4. Permite que os participantes respondam quando acharem conveniente;

5. Não expõe os pesquisados à influência de um entrevistador.

Dessa forma, o questionário foi considerado o instrumento de pesquisa mais adequado às necessidades do projeto, especialmente por possibilitar o uso de ferramentas online na aplicação das perguntas a várias pessoas, de forma rápida e objetiva.

A etapa de coleta de dados para entendimento do público deste projeto apresenta-se disposta em duas etapas: estimativa numérica do público pretendido e aplicação de questionário.

\subsubsection{Público-Alvo}

Estima-se que cerca de 25 mil pessoas circulem pela universidade diariamente ${ }^{1}$. Neste contexto, é possível considerar que o projeto é aberto a qualquer classe social, gênero, idade ou nacionalidade. No entanto, o foco principal está no público que frequenta diariamente a UFES, por se tratar de um aplicativo pensado para uso cotidiano no espaço da universidade. O público frequente foi dividido em três grandes grupos: alunos, docentes e técnicos administrativos.

De acordo com os dados disponibilizados pela própria universidade, por meio de consulta realizada em 2018 via Lei de Acesso à Informação, o grupo "alunos" possui atualmente 15.231 indivíduos, com idade média entre 19 a 24 anos. O grupo "docentes", por sua vez, é composto por 1217 professores, enquanto os servidores administrativos são estimados em 1094 pessoas.

Apesar dos grupos "servidores administrativos" e "docentes" comporem um maior grupo chamado "servidores públicos", sua separação em grupos distintos se deu em função da estimativa de tempo de permanência diária de cada um no campus, totalizando entre 35 a 45 horas semanais para os servidores administrativos e uma média de 16 horas semanais para os docentes. A distinção foi feita porque entende-se, a partir da observação cotidiana da autora na universidade, que o tempo de convívio com o espaço tende a interferir na maneira como se lida com o mesmo.

\subsubsection{Questionário}

Para compreender melhor o interesse do público da universidade quanto ao consumo de frutas do campus e possíveis requisitos funcionais para o aplicativo foi realizada pesquisa por meio de questionário online, através da ferramenta Formulários Google ${ }^{2}$. O questionário foi divulgado no grupo de discussão "UFES" no Facebook, que possui cerca de 27 mil membros, dentre alunos, exalunos, professores e servidores da universidade.

O questionário aplicado foi estruturado em sete perguntas: cinco são de natureza fechada, com alternativas previamente definidas, e duas de natureza aberta, que possibilitaram respostas textuais de caráter livre. O roteiro utilizado no questionário é discriminado no Quadro 1.

1 Dados disponibilizados no site da universidade. Disponível em: http://www.ufes.br/campus-de-goiabeiras Acesso em: 01 de abril de 2018.

2 Ferramenta de criação de formulários da Google. Disponível em: <https://www.google.com/forms/about/> Acesso em: 15 de julho de 2017 
Quadro 1 - Roteiro de perguntas

Pergunta 1

Você alguma vez já consumiu frutas das árvores da UFES?

( ) $\operatorname{sim}$

( ) não

\section{Para os entrevistados que responderam sim:}

\section{Pergunta 2}

Com qual frequência você consome as frutas?

( ) todo dia
( ) uma vez por semana
( ) uma vez por mês

Pergunta 3

Em que momento você consome as frutas?

( ) no intervalo da aula

( ) entre as refeições principais

( ) após o almoço

( ) após a janta

( ) em casa

( ) outros

Pergunta 4

Você costuma procurar árvores frutíferas pelo campus?

( ) $\operatorname{sim}$

( ) não

Pergunta 5

Como você identifica as árvores com frutos maduros?

Para os entrevistados que responderam não na pergunta de número 1:

Pergunta 2
Por que você não consome as frutas?

( ) porque não tenho o costume de comer frutas.

( ) porque não encontro frutas maduras pelo campus.

( ) porque não sabia que tinha árvores frutíferas na UFES.

() outros

\section{Para ambos os entrevistados:}

Disponibilizado por sete dias, o questionário obteve 358 respostas que auxiliaram na identificação das principais demandas dos participantes quanto às árvores frutíferas da universidade, além de apresentar dados que possibilitam a estruturação de um cenário real para desenvolvimento do projeto. 


\subsection{Análise e Interpretação dos Dados}

A fase posterior à coleta de dados é compreendida pelo processo de análise e interpretação dos dados que implicam, por sua vez, na organização dos dados obtidos e na procura do sentido mais amplo das respostas, respectivamente (GIL, 2010).

\subsubsection{Análise Quantitativa}

O desenvolvimento dessa etapa de análise consistiu, primeiramente, na categorização e, posteriormente, na quantificação das ocorrências de cada classe de resposta. A categorização é predominantemente derivada dos próprios dados e consiste numa etapa simples, objetivando organizar as respostas para que possam ser adequadamente analisadas.

De acordo com as definições de Selltiz et al. (1967, p.441 apud Gil, 2010, p.157), as categorias devem atender algumas regras básicas:

1. As categorias devem ser derivadas de um único princípio de classificação, evitandose critérios diversos de diferenciação;

2. O conjunto de categorias deve ser exaustivo, isto é, não deve haver elementos do conjunto que não possam ser atribuídos a uma das categorias;

3. As categorias do conjunto devem ser mutuamente exclusivas, a fim de explicitar a diferenciação entre categorias.

Para facilitar a identificação dos usuários, criou-se duas categorias principais, uma para as respostas daqueles que consomem frutas da universidade e outra para os que não consomem. Essas categorias principais foram subdivididas em outras duas categorias cada, a fim de exaurir possibilidades de respostas diferentes que cada categoria principal viria a ter.

As categorias definidas para análise são listadas a seguir:

1. Pessoas que comem frutas das árvores da UFES

a. ... e possuem o costume de procurá-las pelo campus

b. ... e não as procuram pelo campus

2. Pessoas que nunca consumiram frutas das árvores da UFES

a. ... porque não encontram frutas maduras pelo campus

b. ... porque sequer sabiam que existiam árvores frutíferas na universidade.

Para melhor entendimento e adequação ao tema proposto, as quatro categorias acima foram tratadas como perfis de usuários. As demais respostas eventualmente não enquadradas nas categorias acima compuseram uma categoria residual que foi desconsiderada nas etapas seguintes por envolver poucos elementos.

As frequências de respostas às perguntas fechadas foram obtidas por contagem simples, com os seguintes resultados quantitativos: 
- $58,1 \%$ (208) disseram ter consumido frutas de árvores do campus Goiabeiras, sendo:

- $79,3 \%$ consomem as frutas sempre que as encontram disponíveis, consumindo-as preferencialmente no intervalo das aulas; e

- 46,2\% procura árvores frutíferas, identificando-as predominantemente pelo aspecto visual e por conter frutas caídas ao chão;

- Dos 150 que não consomem as frutas:

○ 44,7\% não o fazem por não encontrarem frutas maduras pelo campus;

- $42,7 \%$ não tinham conhecimento das árvores frutíferas.

Sendo assim, foram delimitados os seguintes perfis de usuário preliminares:

- Perfil 1 - consome frutas do campus e tem costume de procurá-las: 96 pessoas;

- Perfil 2 - comem frutas, mas não as procuram pelo campus: 112 pessoas;

- Perfil 3 - não consome frutas porque não encontram destas maduras: 67 pessoas; e

- Perfil 4 - não consome por não saber das árvores frutíferas: 64 pessoas.

Os dados analisados de forma quantitativa apresentaram um panorama quanto ao consumo ou não das frutas da universidade, mas por si só não forneceram insumos significativos sobre as necessidades destes usuários e sua tradução como requisitos funcionais para o aplicativo.

Assim, utilizou-se de abordagem qualitativa na avaliação das respostas discursivas obtidas pelo questionário para, a partir do discurso textual fornecido pelos participantes, estimar as reais necessidades dos usuários.

\subsubsection{Análise Qualitativa}

Dada a diversidade de respostas para perguntas abertas, a análise qualitativa desses dados depende da adoção de estratégias pelo pesquisador (Gil, 2010, p.177 apud Tesch, 1990):

A manipulação qualitativa dos dados durante a análise é uma atividade eclética; não há uma única maneira de fazê-la. Embora se reconheça a importância de um arcabouço metodológico sólido, não se pode dispensar a criatividade do pesquisador. Cabe-Ihe muitas vezes desenvolver sua própria metodologia. (GIL, 2010, p.177 apud Tesch, 1990)

Por isso, considera-se a análise qualitativa de dados como um processo que permite liberdade por parte do pesquisador, a partir dos objetivos da pesquisa e os tipos de informações obtidos.

Considerando esta afirmativa, nesta pesquisa foram estabelecidas algumas diretrizes para o desenvolvimento da análise qualitativa que, por sua vez, não obedeceram com rigor a uma metodologia específica preexistente, mas que levaram em consideração as etapas básicas de análise de dados: classificação, codificação e tabulação.

Feita esta contextualização, passa-se à apresentação do foco deste artigo: o método utilizado e os resultados da análise qualitativa das respostas para as perguntas abertas. 


\section{Método utilizado na análise qualitativa}

Nesta pesquisa, o processo de análise das respostas à pergunta aberta "Na sua opinião, o que deveria ser feito para facilitar o consumo das frutas da universidade? " considerou as seguintes etapas:

- Leitura e entendimento do conteúdo das respostas fornecidas pelos participantes;

- Segmentação das respostas de acordo com os perfis gerados na análise quantitativa;

- Codificação de trechos das respostas por meio do software NVivo;

- Agrupamento e adaptação dos códigos a partir do amadurecimento da análise;

- Tabulação dos códigos;

- Visualização das frequências dos códigos com auxílio do software Processing.

- Interpretação das frequências a partir da visualização gerada.

As etapas são descritas na seção seguinte, junto com seus resultados.

\section{Etapas e resultados}

A análise iniciou-se com a leitura inicial de todas as respostas fornecidas pelos participantes na intenção de compreender, de forma genérica, o posicionamento dos indivíduos que compõem a amostragem. Esta etapa inicial apresentou-se de suma importância, visto que possibilitou uma visão mais abrangente do contexto antes da análise individual dos conteúdos.

Utilizando o princípio de classificação descrito na etapa de análise quantitativa, as respostas à pergunta analisada foram segmentadas de acordo com os perfis gerados, favorecendo, posteriormente, a tabulação dos dados.

A partir disso, iniciou-se a codificação das respostas. Segundo Charmaz, "codificar significa associar marcadores a segmentos de dados que representam aquilo de que se trata cada um dos segmentos" (2009, p.16). "A codificação é o elo fundamental entre a coleta dos dados e o desenvolvimento de uma teoria emergente para explicar esses dados. Pela codificação, você define o que ocorre nos dados e começa a debater-se com o que isso significa" (CHARMAZ, 2009, p.72, grifo do autor).

Esta primeira etapa foi realizada com o auxílio do software $\mathrm{NVivo}^{3}$. O software é produzido pela empresa QSR International, e tem como proposta auxiliar na análise de dados textuais, gráficos e audiovisuais.

A partir das ferramentas disponibilizadas pelo NVivo, foi possível codificar cada trecho das respostas fornecidas, associando posicionamentos nos discursos a marcadores classificatórios, a fim de compreender a frequência de ocorrência das sugestões apresentadas. 
Numa segunda etapa de leitura, iniciou-se a identificação de trechos semelhantes entre as respostas a partir dos códigos que eram criados a cada novo posicionamento até então não identificado. Conforme Charmaz (2009), os códigos surgem à medida que uma análise minuciosa é realizada, e os significados a partir deles são definidos. Sempre que necessário, foram utilizadas dois ou mais códigos na identificação do conteúdo, objetivando encontrar padrões nas respostas analisadas.

Na terceira etapa de leitura, já em posse de inúmeros códigos criados, percebeu-se a necessidade do agrupamento e adaptação de alguns deles, visto que o entendimento das informações e sua interpretação foram amadurecendo ao longo da análise.

Ao final do processo, quinze codificações foram utilizadas na identificação das necessidades dos usuários. Abaixo segue o Quadro 2, que apresenta os códigos e respectivos exemplos de trechos reais por eles codificados.

Quadro 2 - Quadro de códigos (continua na página seguinte)

\begin{tabular}{lll}
\hline Título do código & Significado a partir das falas & Exemplo de trecho codificado \\
\hline $\begin{array}{l}\text { Acesso às } \\
\text { árvores }\end{array}$ & $\begin{array}{l}\text { Vontade de ter "acesso às árvores" } \\
\text { sem necessariamente dizer como. }\end{array}$ & \\
\hline $\begin{array}{l}\text { Conscientização } \\
\text { quanto a época } \\
\text { de colheita }\end{array}$ & $\begin{array}{l}\text { Menção à importância de esperar } \\
\text { a época adequada de colheita de } \\
\text { um determinado fruto. }\end{array}$ & $\begin{array}{l}\text { "...]acho que conscientizar as pessoas mesmo, pois muitas } \\
\text { pegam os frutos antes de amadurecerem, evitando assim } \\
\text { que crescem e possam ter condições de prosperar" }\end{array}$ \\
\hline Disponibilização & $\begin{array}{l}\text { Proposta de disponibilização das } \\
\text { frutas já colhidas para os alunos, } \\
\text { independente de quem as colha. }\end{array}$ & $\begin{array}{l}\text { "Seria legal se a gente fizesse uma coleta dos frutos, } \\
\text { dividindo os alunos em grupo para facilitar e agilizar o } \\
\text { serviço. Depois, poderíamos fazer tipo uma feirinha em } \\
\text { lugares bem frequentados por todos os estudantes, como } \\
\text { por exemplo, em frente o RU, disponibilizando essas frutas } \\
\text { para todos" }\end{array}$ \\
\hline $\begin{array}{l}\text { Divulgação } \\
\text { Fruta }\end{array}$ & $\begin{array}{l}\text { Falta de divulgação para a } \\
\text { comunidade acadêmica quanto à } \\
\text { existência dessas árvores. }\end{array}$ & $\begin{array}{l}\text { "Talvez o que realmente falta é a divulgação dessas } \\
\text { [...]" }\end{array}$ \\
\hline $\begin{array}{l}\text { Incerteza do participante quanto à } \\
\text { possibilidade de consumo de uma } \\
\text { dada fruta. }\end{array}$ & $\begin{array}{l}\text { "Identificar as árvores frutíferas e colocar uma placa } \\
\text { sinalizando que o consumo pode ser realizado e se possivel } \\
\text { falar dos benefícios da fruta para a nossa saúde" }\end{array}$ \\
\hline
\end{tabular}


Quadro 2 - Quadro de códigos (continuação).

\begin{tabular}{|c|c|c|}
\hline Código & Significado a partir das falas & Exemplo de trecho codificado \\
\hline $\begin{array}{l}\text { Facilitar a } \\
\text { colheita }\end{array}$ & $\begin{array}{l}\text { Disponibilização de utensílios que } \\
\text { pudessem facilitar a colheita dos } \\
\text { frutos, visto que muitos se } \\
\text { encontravam em locais altos. }\end{array}$ & $\begin{array}{l}\text { "Que as maiores não fossem podadas tantas vezes, pois } \\
\text { acabam com os galhos acessíveis, ou então visto que a } \\
\text { poda é necessária que fossem disponibilizadas escadas ou } \\
\text { colhedores feitos com garrafas pets e canos de pvc para a } \\
\text { colheita" }\end{array}$ \\
\hline
\end{tabular}

$\begin{array}{ll}\text { Hábito de } & \text { Hábito de consumo das frutas } \\ \text { consumo } & \text { como fator determinante para a } \\ & \text { solução do problema apresentado. }\end{array}$

\begin{tabular}{lll}
\hline Identificação & Interesse na identificação da & "Placas com identificação de espécies de árvores e \\
& $\begin{array}{l}\text { árvore e/ou fruto, independente } \\
\text { do meio a ser utilizado. }\end{array}$ & $\begin{array}{l}\text { contendo a informação em que período é a época em que } \\
\text { as mesmas vão 'dar' frutas" }\end{array}$ \\
\hline
\end{tabular}

\begin{tabular}{|c|c|c|}
\hline Incentivo & $\begin{array}{l}\text { Falta de incentivo da universidade } \\
\text { ao consumo das frutas. }\end{array}$ & "Falta informação e incentivo" \\
\hline $\begin{array}{l}\text { Informações } \\
\text { genéricas }\end{array}$ & $\begin{array}{l}\text { Solicitam "informações", sem } \\
\text { qualquer outro detalhe ou } \\
\text { especificação quanto ao tipo de } \\
\text { informação solicitada. }\end{array}$ & $\begin{array}{l}\text { "Inicialmente as árvores frutíferas deveriam ser mais } \\
\text { cuidadas, assim como as outras, e poderia haver alguma } \\
\text { forma de sinalização e informações sobre a árvore e as } \\
\text { frutas, assim facilitaria o consumo" }\end{array}$ \\
\hline
\end{tabular}

\begin{tabular}{lll}
\hline Localização & Respostas que manifestam & "Um lugar com informações sobre a localização das \\
& interesse no conhecimento da & árvores e época dos frutos seria ótimo. "
\end{tabular}
localização das plantas, independente do meio.

\begin{tabular}{lll}
\hline $\begin{array}{l}\text { Manutenção e } \\
\text { cuidado }\end{array}$ & $\begin{array}{l}\text { Referência à manutenção e } \\
\text { cuidado das plantas e/ou campus. }\end{array}$ & $\begin{array}{l}\text { "Primeiro você poder chegar nas árvores, que com os } \\
\text { matos gigantes que estão em alguns lugares é } \\
\text { impossível[...]" }\end{array}$ \\
\hline Plantio & $\begin{array}{l}\text { Necessidade de plantio de mais } \\
\text { árvores frutíferas no campus. }\end{array}$ & $\begin{array}{l}\text { "Criar pequenas áreas de plantio de árvores frutíferas, onde } \\
\text { elas pudessem ser colhidas e comidas diretamente do pé. }\end{array}$ \\
\hline Receio de coleta & $\begin{array}{l}\text { Fragmento da resposta codificado } \\
\text { apresenta receio quanto a coleta } \\
\text { do fruto por parte do indivíduo. }\end{array}$ & \\
\hline Sazonalidade & $\begin{array}{l}\text { Importância de conhecer a } \\
\text { sazonalidade dos frutos, a fim de } \\
\text { facilitar a procura dos frutos na } \\
\text { sua época de amadurecimento. }\end{array}$ & $\begin{array}{l}\text { eu não lembro de ver ou não sei que está com fruta } \\
\text { mad...] }]\end{array}$ \\
\hline
\end{tabular}

Fonte: próprio autor

Para dar sequência à análise, foi necessário submeter os códigos a uma tabulação, de modo a sintetizar os dados e verificar o que significam para a pesquisa. O termo tabulação

[...] serve para designar o processo pelo qual se apresentam graficamente os dados obtidos das categorias, em colunas e linhas verticais, permitindo sintetizar os dados de observação, de maneira a serem compreendidos e interpretados rapidamente e ensejando apreender-se com um só olhar as particularidades e relações dos mesmos (RUDIO, 2002, p.125). 
A tabulação desses códigos, por sua vez, consistiu na contagem das frequências de ocorrência de cada código. A tabulação, segmentada pelos perfis identificados, originou o gráfico 1.

Gráfico 1 - Tabulação dos códigos

\begin{tabular}{|c|c|c|c|c|c|}
\hline & Perfil 1 & Perfil 2 & Perfil 3 & Perfil 4 & Total \\
\hline Manutenção e cuidado & 21 & 10 & 4 & 6 & 41 \\
\hline Identificação & 21 & 27 & 21 & 12 & 81 \\
\hline Plantio de mais árvores & 17 & 18 & 5 & ○ & \\
\hline Facilitar a colheita & 19 & 25 & & O & \\
\hline Localização & 14 & 20 & 10 & 14 & \\
\hline Sazonalidade & 12 & 9 & & 8 & \\
\hline Divulgação & 9 & 9 & 16 & 11 & 45 \\
\hline Disponibilização Ufes & 7 & 11 & 9 & 11 & 38 \\
\hline Conscientização (colheita) & ○ & 0 & - & 4 & 11 \\
\hline Receito de coleta & - & - & & - & 5 \\
\hline Incentivo & - & ○ & 4 & O & 11 \\
\hline Acesso as árvores & - & 0 & & & 4 \\
\hline Fruta comestivel & - & 0 & 0 & - & 7 \\
\hline Hábito de consumo & & & - & & e \\
\hline Informaçōes genéricas & ○ & 5 & - & 4 & 14 \\
\hline
\end{tabular}

No gráfico 1 pode-se observar a ocorrência das respostas de acordo com cada perfil gerado. No eixo vertical estão representadas as necessidades dos usuários-alvo identificadas nas respostas ao questionário (códigos), enquanto no eixo horizontal estão os perfis de usuários previamente criados - baseados nas categorias estabelecidas considerando as questões objetivas que antecedem a pergunta discursiva - seguidos do "Total". 
A partir desta análise, quatro principais necessidades foram identificadas, independente dos perfis considerados:

1. Árvores/frutos deveriam ter sua localização conhecida e sua espécie identificada;

2. Divulgação e incentivo ao consumo de frutas das árvores existentes no campus;

3. Disponibilização de ferramentas adequadas para facilitar colheita, visto que a maioria das árvores são altas e os frutos, por sua vez, de difícil alcance;

4. Melhor manutenção e cuidado do espaço verde do campus, com muitas menções à falta de podas para o crescimento saudável das plantas, além do difícil acesso às árvores devido à grama alta.

Destaca-se que dentre as quatro principais necessidades dos usuários, apenas as duas primeiras esperam ser solucionadas com o desenvolvimento do aplicativo. As necessidades 3 e 4 são iniciativas que estão fora do escopo digital e dependem de ações de outra natureza.

Além disso, a partir da interpretação dos dados apresentados pelo gráfico, pôde-se inferir determinadas características aos perfis dos usuários anteriormente definidos. Essas características, oriundas dos códigos gerados e dos trechos por eles codificados, são apresentadas a seguir:

\section{Perfil 1 - Procura e consome frutas sempre que as encontra disponíveis}

- Costuma procurar frutas no campus para consumo;

- Apresenta preocupação com o cuidado e a manutenção do meio ambiente;

- Gostaria que as árvores frutíferas fossem de mais fácil identificação;

- Sugere que as árvores tenham ao seu redor alguma ferramenta que auxilie na retirada de frutas dos locais mais altos;

- Defende a plantação de mais árvores frutíferas, de preferência em locais de fácil acesso, que resulte numa espécie de pomar comunitário;

- Gostaria de conhecer melhor a sazonalidade das frutíferas do campus, a fim de procurar as frutas em datas favoráveis.

\section{Perfil 2 - Sem costume de procurar as frutas, mas consome quando de fácil acesso}

- Não costuma procurar as frutas, consumindo-as apenas quando em fácil acesso;

- Gostaria que as árvores fossem sinalizadas, de modo a chamar mais a sua atenção;

- Reclama o difícil acesso algumas frutas, devido à altura das árvores, e gostaria que fossem disponibilizados meios para facilitar a coleta;

- Quer conhecer a localização das árvores, a fim de descobrir se há mais árvores do seu interesse no perímetro cotidiano;

- Acredita que deveriam ser plantadas mais árvores frutíferas. 
Perfil 3 - Não consome frutas do campus por não saber que lá havia árvores frutíferas

- Sequer sabia da existência de árvores frutíferas no campus;

- Gostaria que as árvores fossem identificadas com nome e fruto produzido, até mesmo não estando com frutos maduros, apenas para conhecimento;

- Gostaria de obter mais informações sobre as árvores, inclusive sobre sua existência, e acha que falta divulgação pela universidade;

- Entende que conhecer a localização é crucial para incentivar o consumo das frutas;

\section{Perfil 4 - Não consome frutas pois alega que nunca encontrou frutas maduras disponíveis}

- Sabia das árvores, mas não consome frutas por não achar maduras disponíveis;

- Gostaria de saber a localização e identificação dessas árvores;

- Acredita que falta divulgação, principalmente nas redes sociais;

- Acredita que a universidade poderia colher esses frutos e disponibilizar aos alunos no restaurante universitário.

Gráfico 2 e 3 - Relação de semelhança entre os perfis 1 e 2 e 3 e 4, respectivamente

Divulgação

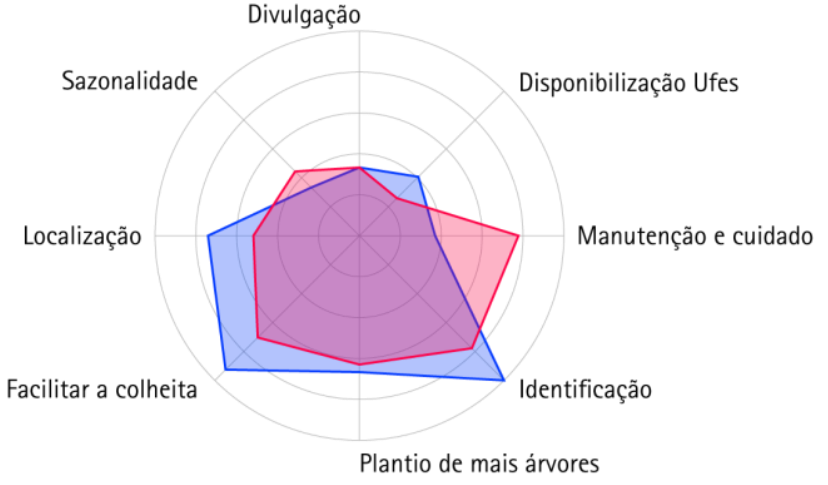

Perfil 1

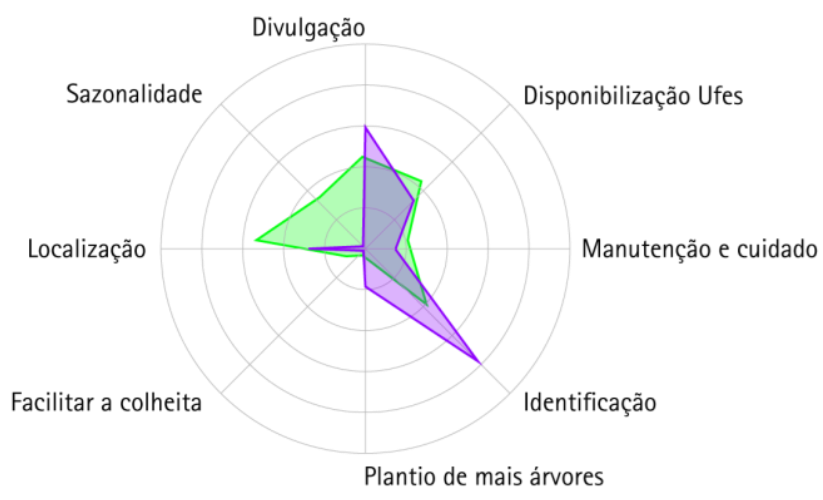

Perfil 3

Perfil 4

Fonte: autora 


\section{Conclusão}

Como já foi dito, é fundamental definir inicialmente em design de interação os perfis de usuário relacionados a um projeto, bem como suas características e necessidades.

O método de análise proposto se mostrou efetivo para analisar os dados diversos obtidos a partir de pergunta aberta do questionário, e assim definir aspectos que pudessem ser agrupados em perfis definidos de forma quantitativa.

Ainda em relação ao método utilizado, entende-se como importante observar a pesquisa por meio do design e o design a partir da pesquisa. Observou-se uma interessante correlação entre pesquisa e design nas etapas da análise qualitativa.

Foi fundamental tanto haver uma abordagem analítica, com a obtenção de dados por formulário e sua posterior análise quantitativa, bem como uma abordagem mais generativa, como a iteração de insights para definição de códigos e a visualização de informações para facilitar a análise por meio do software Processing (STAPPERS e GIACCARDI, 2013).

Estes aprendizados permitiram o amadurecimento da análise qualitativa de respostas abertas, e geraram importantes subsídios para as próximas etapas do projeto. Embora os dados não possam ser amplamente generalizados, considerando-se ser originados de uma amostragem relativamente pequena de participantes em relação ao universo de frequentadores da UFES, os resultados reforçaram suposições anteriores e oferecem insumos significativos para tomada de decisões frente ao projeto proposto.

As personas definidas serviram como base para a etapa seguinte de proposição de protótipos preliminares para o aplicativo de auxílio ao consumo de frutas no campus universitário. Entende-se que os resultados ajudarão a fornecer um aplicativo mais adequado às necessidades da comunidade e, assim, favorecendo uma vida mais saudável, consciente e integrada ao espaço aos frequentadores do campus universitário.

\section{Referências}

CHARMAZ, K. A construção da teoria fundamentada: Guia prático para análise qualitativa. São Paulo: Bookman, 2009.

GIL, Antônio C. Métodos e técnicas de pesquisa social. 6.ed. São Paulo: Atlas, 2010.

MAYHEW, Deborah J. The Usability Engineering Lifecycle: a practitioner's handbook for user interface design. San Francisco, Morgan Kaufmann, 1999, 4th ed.

PREECE, J., ROGERS, Y., SHARP, H. Design de interação: além da interação homem-computador. Porto Alegre: Bookman, 2005.

RUDIO, Franz V. Introdução ao projeto de pesquisa científica. 30.ed. Petrópolis: Vozes, 2002.

STAPPERS, Pieter; GIACCARDI, Elisa. 43. Research through Design. In: SOEGAARD, Mads; DAM, Rikke Friis. The Encyclopedia of Human-Computer Interaction, 2nd Ed. The Interaction Design Foundation, January 2013. On-line. Disponível em: https://www.interactiondesign.org/literature/book/the-encyclopedia-of-human-computer-interaction-2nd-ed/researchthrough-design. Acesso em: 04 de abril de 2018. 